\title{
INTRODUÇÕES E CONSIDERAÇÕES FINAIS DO GÊNERO MONOGRAFIA: UMA ANÁLISE DAS ESTRATÉGIAS DE REFERÊNCIAÇÃO E PROCESSOS DE RETOMADA À LUZ DA LINGUÍSTICA TEXTUAL
}

\author{
INTRODUCTIONS AND FINAL CONSIDERATIONS OF THE GENDER \\ MONOGRAPHY: AN ANALYSIS OF REFERENCE STRATEGIES AND \\ PROCESSES FOR THE RETURN TO LIGHT OF TEXTUAL LINGUISTICS
}

\author{
Gilvan Santos GONÇALVES ${ }^{1}$ \\ Nayara da Silva QUEIROZ ${ }^{2}$
}

\begin{abstract}
${ }^{1}$ Universidade Estadual do Maranhão (UEMA). E-mail: gilvansantosg@outlook.com.br. ${ }^{2}$ Universidade do Vale do Taquari- UNIVATES. E-mail: nayaraqueiroz01@ hotmail.com.
\end{abstract}

Artigo submetido em 05/03/2019, aceito em 15/06/2019 e publicado em 15/09/2019.

\begin{abstract}
RESUMO: Este artigo faz uma abordagem a respeito das principais estratégias de referenciação, progressão e cadeias referenciais utilizadas em introduções e considerações finais do gênero monografia. $\mathrm{O}$ objetivo é mostrar a organização e os processos de retomada textual desses componentes à luz da Linguística Textual, para isso utilizou-se uma abordagem teórico-metodológica da análise de gênero, baseada na nova retórica de Miller (1984, 2012), Bazerman (2005), Koch $(2006,2009)$. No processo de dados, o corpus a ser investigado constituir-se-á de monografias produzidas nos anos letivos de 2012 e 2013, no curso de Letras Licenciatura da Universidade Estadual do Maranhão (UEMA). A caracterização dessas estratégias de referenciação evidenciou as escolhas linguísticas e mostrou as dificuldades encontradas pelos alunos na construção argumentativa de suas introduções e considerações finais, mostrando o desconhecimento de estratégias de retomadas nesses subgêneros textuais, tanto no que se refere à temática ou problemática levantada na introdução, que deveria ser explorada nas considerações finais, quanto ao uso de termos que poderiam evitar a repetição do termo utilizado para o objeto-do-discurso.
\end{abstract}

Palavras-chave: Introduções; Considerações Finais; Referenciação.

ABSTRACT: This article makes an approach regarding the main reference strategies, referential progression and referential chains used in introductions and final considerations of the monograph genre. The objective is to show the organization and the processes of textual retrieval of these components in the light of Textual Linguistics, for which a theoreticalmethodological approach of the gender analysis was used, based on Miller's new rhetoric (1984, 2012), Bazerman ), Koch (2006, 2009). In the data process, the corpus to be investigated will consist of monographs produced in the academic years of 2012 and 2013, in the course of Letters graduation of the State University of Maranhão (UEMA). The characterization of these reference strategies will show the linguistic choices and will show 
the difficulties encountered by the students in the argumentative construction of their introductions and final considerations, showing the lack of knowledge of strategies of retakes in these textual subgeneric, both with regard to the thematic or problematic raised in the introduction, which should be explored in the final considerations, regarding the use of terms that could avoid the repetition of the term used for the speech object.

Keywords: Introductions; Final considerations; Reference.

\section{INTRODUÇÃO}

Esta pesquisa tem como objetivo mostrar a organização e os processos de retomada textual principais estratégias de referenciação, progressão e cadeias referenciais utilizadas em introduções e considerações finais do gênero monografia à luz da Linguística Textual. O intuito é analisar como os setores sociais que interagem nesse espaço institucional fazem uso das estratégias de referenciação para criar novas realidades de significação, relações sociais e organizar o sistema de atividades desse grupo social. Para alcançarmos o nosso objetivo, utilizamos como referencial teórico-metodológico abordagens que recobrem, principalmente, à nova retórica Miller (1984), Bazerman (2005) e Koch $(2006,2009)$.

De acordo com Bazerman (2005.p.22), como evento discursivo, os gêneros são práticas mediadoras que constituem na dimensão textual as relações sociais estabelecidas para a realização de textos nos sistemas de gêneros e nos sistemas de atividades pode ajudar a entender como interromper ou mudar os sistemas pela exclusão, adição, ou modificação de um tipo de documento. $\mathrm{O}$ processo de progressão referencial ocorre por meio de estratégias variadas. Os objetos de discurso são construídos e reconstruídos ao longo da atividade discursiva. As formas como são construídos ou reconstruídos estão intrinsecamente relacionadas a propósitos comunicativos do produtor do texto, como afirma Koch (2009, p. 133-134). São escolhas orientadas pelo princípio de subjetividade.
Nesse sentido, Miller (1984) argumenta que, para uma teoria de gêneros, o mais importante seria o fato de as situações retóricas serem recorrentes, porque, assim, podemos tipificá-las por meio das similaridades e semelhanças importantes tanto em sua forma quanto em sua substância. Ou seja, as diversas formas de descrições linguísticas, dentro da vasta existência de variedade escrita e falada da linguagem, sempre foram estabelecidas e contextualizadas em padrões de uso linguístico que hoje ganharam o nome de texto ou gênero escrito. Embora todas as formas de gênero escrito abordem compreensões das variações linguísticas, a escrita em forma de gênero evidencia, de certa maneira, o saber pedagógico, a intertextualidade e o ensino de seu produtor, como leitor assíduo de outros textos com retóricas e gêneros diferenciados.

Koch (2006, p. 101) observa que no processo de leitura e construção dos textos, levamos em conta que a escrita e a fala baseiam-se em formas padrão e relativamente estáveis de estruturação e é por essa razão que, cotidianamente, em nossas atividades comunicativas, são às vezes em que somente lemos textos diversos, como também produzimos ou ouvimos enunciados.

Nesse contexto, para nosso estudo, o corpus deste artigo é composto de diferentes introduções e considerações finais do gênero monografia apresentadas no curso de Letras da Universidade Estadual do Maranhão, escolhidas aleatoriamente, inseridas no sistema de gêneros utilizados nas interações acadêmicas e do sistema de atividades 
estruturadas dentro de uma comunidade discursiva e acadêmica.

\section{O CONCEITO DE PROGRESSÃO REFERENCIAL}

Os processos de referenciação e progressão referencial são importantes estratégias de introdução por meio das quais são evidenciadas novas entidades que servem de base a novos referentes a serem abordados dentro de um texto. Essas estratégias são atividades discursivas que constroem anafórica e cataforicamente a repetição ou progressão de novos elementos linguísticos que, por sua vez, sempre remetem a cadeias referenciais descritas, narradas ou expostas, dependendo da organização e do projeto de sentido que se quer rotular no tema ou título de um determinado enunciado.

O processo linguístico e discursivo de um texto, como atividade discursiva que venha a ser abordada em uma profunda e possível análise, deve sempre ter uma justificativa em relação ao seu esquema de composição, organização e orientação temática, propósito e partes constituintes que lhe darão efeitos de sentidos decorrentes da escolha de seus elementos lexicais e sintáticos.

Ao lermos um texto, seja qual for o gênero e tipologia, devemos procurar identificar o campo social discursivo em que o enunciado (objeto de discurso) se insere, seja ele no contexto científico, didático, político ou literário. Primeiramente, é obrigatório identificar e conhecer o tema, bem como a sua competência discursiva, sua progressão (continuidade), sua retomada e segmentação em relação ao seu tema central e introdutório.

A respeito dessa orientação, Koch (2006, p.113) afirma que todo e qualquer gênero textual possui estilo; em alguns deles, há a condições mais favoráveis (gêneros literários), em outros, menos favoráveis (documentos oficiais, notas fiscais), para a manifestação do estilo individual. Por sua vez, Bazerman (2005, p.31) afirma que os gêneros tipificam muitas coisas além da forma textual. A primeira análise de um determinado gênero textual nos ajuda de início a começar entender o propósito comunicativo de um enunciado, e se esse propósito é parte ou não de uma atividade linguística que pode ser entendida obedecendo aos diversos padrões organizacionais que identificam e o constituem, sobretudo dos gêneros encontrados em textos (narrativos, expositivos, dissertativos e injuntivos).

De acordo com Antunes (2006.p.51), em síntese, com a análise de textos, pretendemos desenvolver nossa capacidade de perceber as propriedades, as estratégias, os meios, os recursos, os efeitos, enfim, as regularidades implicadas no funcionamento da língua em processos comunicativos de sociedades concretas, o que envolve a produção e a circulação de todos os tipos de textos-em-função; ou seja, a referenciação como atividade discursiva diz respeito às formas de introdução das novas entidades e referentes a serem alocados no texto, e esses referentes podem ser retomados mais adiante ou servirem de base para a introdução de novos referentes.

\section{A REFERENCIAÇÃO: UMA ESCOLHA LINGUÍSTICO- DISCURSIVA}

A referenciaçao é um tipo de atividade discursiva por meio do qual se constroem os diferentes objetos de discurso que podem ser mantidos ou desfocalizados na plurinealidade do texto. No processo de referenciação, é importante apresentar todos os significados linguísticos do referente do discurso. As principais estratégias de progressão referencial a serem alocadas em um texto devem ser dadas através de dois processos: ativação e reativação.

Os gêneros textuais são formados por sequências diferenciadas denominadas tipos textuais. Os tipos textuais constituem 
sequências linguísticas ou sequências de enunciados, não são textos linguísticos nem textos empíricos. A presença de vários tipos textuais em um gênero é denominada de heterogeneidade tipológica. O gênero textual é formado por tipos textuais diferentes como: descritivo, argumentativo e injuntivo.

Nesse sentido, Koch (2006, p.113) afirma que os gêneros não são instrumentos rígidos e estanques, o que quer dizer que "a plasticidade e a dinamicidade não são características intrínsecas ou inatas dos gêneros, mas decorrem da dinâmica da vida social e cultural".

$\mathrm{Na}$ construção de textos e enunciados, é importante estabelecer as formas de progressão referencial, bem como evidenciar sua continuidade (retroação) e progressão. As retomadas ou remissões podem ser realizadas de diversas maneiras, sempre fazendo referências e abordagens intertextuais, pois assim podemos nos apoiar em análises já feitas em outros textos e tomálas com referência. Elas podem ser caracterizadas da seguinte forma:

a. Formas de valor pronominal - como os pronomes propriamente ditos (pessoais de terceira pessoa, pronomes possessivos, pronomes demonstrativos, pronomes demonstrativos, pronomes indefinidos, interrogativos e relativos).

b. Numerais (cardinais, ordinais, multiplicativos e fracionários) contribuem para a progressão referencial.

c. Certos advérbios locativos - conhecidos como dêiticos espaciais (aqui, lá, ali etc.). Os advérbios locativos e algumas expressões adverbiais também têm a função de fazer progredir referencialmente no texto.

d. Elipses e algumas formas nominais reiteradas - desempenham a função de progressão referencial.

e. Formas nominais sinônimas, heteronímicas e até nomes genéricas.

Todos esses elementos servem para enfatizar a progressividade de um texto. É necessário estabelecer um equilíbrio entre duas exigências fundamentais, e elas devem estar relacionadas à retroação e à repetição textual, de forma que sua continuidade não seja desfocalizada, a partir da introdução de novas formas de valor pronominal.

\section{OS PROCESSOS DE RETOMADA E A FUNÇÃO DAS EXPRESSÕES NOMINAIS}

A retomada é a operação responsável pela manutenção em foco, no modelo de discurso, de objetos previamente introduzidos, dando origem às cadeias referenciais ou coesivas, que são responsáveis pela progressão referencial do texto. A referenciação realizada por meio e intermédio das formas pronominais foi sempre descrita na literatura linguística como pronominalização, que pode ser por meio de recursos anafóricos e catafóricos, sempre enfatizando os elementos cotextuais.

Essas formas ou expressões nominais, ao efetuarem a progressão textual, podem desempenhar uma série de funções importantes para a construção dos sentidos do texto. Além disso, desempenham uma série de funções importantes para a construção dos sentidos do texto. No nível microestrutural e macroestrutural, a organização textual também estabelece a coesão textual e, em grande parte, são responsáveis pela introdução de novos referentes, novas sequências e delimitação de novos parágrafos. A seleção das formas ou expressões nominais deve merecer um especial cuidado na construção de todo e qualquer texto, sempre levando em conta que essas formas desempenham um papel de maior relevância na progressão textual e na construção de sentido.

Dentre os conhecimentos pressupostos como partilhados pelos interlocutores, que possuem características ou traços do referente ou locutor de intenções textuais, destacamos as 
expressões nominais, que podem ser retomadas da seguinte maneira:

a. Ativação ou reativação na memória formas de remissão a elementos anteriormente apresentados no texto ou sugeridos pelo co-texto precedente. Elas possibilitam a reativação da memória do interlocutor.

b. Encapsulamento (sumarização) e rotulação - ocorrem da seguinte forma: as nominalizações sumarizam as informações contidas em seguimentos precedentes do texto (informações-suporte), encapsulandoas sob a forma de uma nova expressão nominal, isto é, transformando-as em objetos-de-discurso.

c. Organização macroestrutural - as formas remissivas sinalizam, muitas vezes, que o autor do texto está passando a um estágio seguinte de sua argumentação, por meio do fechamento do anterior, pelo seu encapsulamento numa forma nominal.

d. Atualização de conhecimentos por meio de retomadas realizadas pelo uso de um hiperônimo - ocorrem com o uso de um hiperônimo com função de retomar um termo pouco usual, atualizando, assim, os conhecimentos do interlocutor.

e. Especificação por meio da sequência hiperônimo/hipônimo - trata-se do que chamamos de anáfora especificadora, que ocorre quando se faz necessário um maior refinamento da categorização. Os hiperônimos e hipônimos são termos de um mesmo campo de sentido, em que um deles designa o gênero e o outro a espécie.

f. Construção de paráfrases anáforas deficionais e didáticas - ocorre quando certa paráfrase realizada por expressões nominais tem a função de elaborar definições. Nessas anáforas deficionais o termo técnico a ser definido é o elemento previamente definido e introduzido, sendo que essa definição é aportada pela forma anafórica.

g. Orientação argumentativa - realiza-se pelo uso de termos ou expressões metafóricas ou não. Essa orientação é uma manobra bastante utilizada em textos com gêneros opinativos.

h. Categorização metaenunciativa de um ato de enunciação - realiza a categorização ou avaliação da própria enunciação realizada, assim essas avaliações classificam, nomeiam e constituem uma reflexão do produtor do texto.

Todo gênero textual é marcado por sua esfera de atuação, que promove modos específicos de combinar, indissoluvelmente, o conteúdo temático, o propósito comunicativo, o estilo e a composição de toda a sua estrutura textual. Trata-se de entidades escolhidas, tendo em vista suas esferas temáticas, o conjunto de participantes e a vontade enunciativa ou a intenção de seu produtor, que é o sujeito responsável por seus enunciados, unidades reais e ou concretas de sua comunicação verbal.

$\mathrm{Na}$ categorização metaenunciativa, existem rótulos que enunciam os conteúdos de um determinado segmento textual, caracterizando o seu fato, seu acontecimento, sua situação, sua cena, seu ato, seu evento etc. Os atos de enunciação sempre constituem a reflexão do produtor do texto sobre seu próprio dizer ou sobre o dizer do outro, caso em que, frequentemente, ocorre o uso de aspas para designar o tipo de distanciamento, diferença ou ironia.

\section{PROCESSOS METODOLÓGICOS: MATERIAIS E MÉTODOS}

Uma perspectiva pragmática e funcional contribui para um melhor aproveitamento da produtividade da linguagem e para a criação de um contexto conveniente. $\mathrm{O}$ texto é construído e articulado com coerência, de acordo com os seus aspectos formais, funcionais, retóricos e a sua intenção comunicativa.

Cada aspecto textual relacionado ao seu processo retórico determina uma adaptação de palavras e de frases que, por sua vez, possuem finalidade pretendida. 
Assim, as intenções dos falantes e os efeitos dos enunciados nos interlocutores devem ser considerados no momento da produção do discurso, que será adequado (coerente) a essas intenções e efeitos.

Segundo Miller (2012, p.13), “o gênero fornece uma maneira de trazer a pratica social para o contexto instrucional e encoraja uma atenção cuidadosa às normas e convenções". Em relação aos aspectos retóricos e funcionais de um texto, o objeto de discurso caracteriza-se pelo fato de construir progressivamente uma configuração e identidade que, por meio de seus referentes, enriquece novos aspectos e propriedades, suprimindo aspectos anteriores ou ignorando outros possíveis, que se pode associar com novos aspectos, integrando-os de forma discursiva $e$ articulada.

A seguir, apresentamos os 04 exemplares das introduções e considerações finais das monografias que foram escolhidas aleatoriamente e serviram de base para as respectivas leituras $\mathrm{e}$ análises quanto ao emprego dos aspectos formais, funcionais e retóricos inerentes a sua superestrutura.

\section{MONOGRAFIA 01}

\section{$\checkmark$ Introdução}

$\mathrm{O}$ que é saber ler? $\mathrm{O}$ conceito de leitura está geralmente ligado à decodificação das letras e palavras, mas no atual mundo em que vivemos, $\underline{\mathbf{o}}$ conceito de leitura pode ser muito mais amplo do que geralmente é divulgado.

Todas as conquistas que o homem alcançou no curso de sua história estão de alguma forma relacionadas à linguagem, seja ela escrita ou falada. A questão da leitura é tema de inúmeros livros e discursos de diversos autores, dentre eles destaca-se Paulo Freire (1989, p.9) que afirma: "a leitura do mundo precede sempre a leitura da palavra e a leitura desta implica a continuidade da leitura daquele".

\section{$\checkmark$ Considerações Finais}

Durante esta investigação, discorremos que a leitura é um ato que, também, depende de estímulo e motivação. A prática de leitura é uma tarefa essencial para a construção do conhecimento e um deflagrador da opinião crítica do indivíduo.

Ao propor atividades de leitura aos alunos de Ensino Médio, terceiro ano, nós levamos em conta o gosto que os mesmos possuem pela arte de ler. Sabemos que esta faixa de idade não se sente muito motivada pelo ato de ler por vários fatores: literaturas impostas pelos professores ou ainda porque precisam ler livros impostos pelos mesmos e não sentem atração por esse tipo de leitura.

\section{Análise:}

$\mathrm{Na}$ primeira monografia selecionada, observa-se que, na parte da introdução e da conclusão, o aluno utiliza repetição de palavras. Essa escolha linguística mostra uma incapacidade quanto ao uso de homônimos ou outros recursos que possibilitassem a retomada do referente leitura. Isso está relacionado ao uso excessivo das expressões leitura e ler. Assim, não se utiliza o processo de progressão referencial como a pronominalização e o uso dos encapsulamentos. Esse recurso linguístico é uma forma de coesão textual, que pode ocorrer como uma anáfora ou como uma catáfora.

\section{$\checkmark$ Introdução}

\section{MONOGRAFIA 02}

A fábula é um gênero narrativo que, ao longo dos anos, vem atraindo a atenção das crianças pelo seu lúdico e fantástico e por possuir a figura de animais como as personagens das histórias. $\mathrm{Na}$ antiguidade era utilizada pelos adultos para transmitir lições de moral. Em decorrência da moralidade presente nas fábulas, esse gênero adentra nas escolas com finalidade educativa como objeto de reflexão e julgamento de comportamento. Assim, ele 
acaba sendo explorado com intuito de repassar valores e comportamento socialmente adequados. Partindo da importância de se discutir essa temática, o projeto tem como objetivos investigar a aplicabilidade da narração de história através do gênero fábula, identificar os benefícios trazidos pela narrativa literária às crianças ouvintes e averiguar como os professores utilizam esse gênero para desenvolver a linguagem oral das crianças.

\section{$\checkmark$ Considerações Finais}

Ensinar uma língua vai muito além de se dispor a elencar palavras para que os alunos as absorvam. Ensinar uma segunda língua exige que o professor tenha em mente que o aluno precisa, além de dominar um léxico, atuar dentro da cultura da língua aprendida.

\section{Análise:}

$\mathrm{Na}$ introdução da monografia 02 , o aluno faz uso dos processos de referenciação para retomar adequadamente o referente a fábula ao utilizar os sinônimos gênero e narrativa literária. Entretanto, nas considerações finais, repete o referente ensinar, não fazendo uso de outros termos linguísticos que pudessem fazer a retomada do seu objeto de discurso sem, entretanto, realizar uma repetição tão próxima. Cabe ressaltar que os sinônimos são muito importantes em um texto, já que repetições desnecessárias de termos empobrecem o texto, causam confusão e tornam a leitura monótona.

\section{$\checkmark$ Introdução}

\section{MONOGRAFIA 03}

Dividido em quatro capítulos, o presente trabalho tem como objetivo fazer um estudo acerca dos enunciados de caminhão, com temática religiosa-mística, como mecanismo discursivo relacionado ao processo identitário do caminhoneiro.

Objetiva-se também, analisar as teorias e um breve histórico da análise do discurso de linha francesa, assim como seus principais conceitos, proceder a um estudo acerca da identidade fazendo uma reflexão baseada nas concepções de alguns teóricos, reconhecer a importância dos gêneros discursivos com enfoque em enunciados de caminhão ou frases de parachoque de caminhão e verificar a formação identitária a partir dos enunciados selecionados.

\section{$\checkmark$ Considerações Finais}

A linguagem representa para o homem a materialização de suas ideias, bem como de sua existência. As frases de para-choque de caminhão, denominadas aqui como enunciados de caminhão, apresenta uma linguagem sociointerativa com características específicas de enunciação.

Os enunciados de caminhão estão diretamente ligados a formação discursiva e ideológica e à identidade do caminhoneiro. Em uma relação do enunciado pelo caminhoneiro, as frases são uma espécie de porta voz dos medos, crenças e opiniões desses sujeitos. Outrossim, os enunciados também constituem uma interação social e a linguagem não verbal é comumente utilizada para corroborar o sentido.

Os enunciados com temática religiosa propagam a ideologia cristã, predominante no Brasil, o que ratifica o fato dos enunciados de caminhão [...].

\section{Análise:}

Nessa monografia, na introdução, vê-se o uso de uma estratégia de referenciação, a nominalização, quando utiliza-se o termo frase para retomar a palavra enunciado. Entretanto, nas considerações finais, a repetição mais uma vez revela a falta do uso de estratégias de progressão referencial, tais como a pronominalização ou a nominalização, que permitiriam a retomada adequada do objeto do discurso sem a reprodução insistente do termo enunciado. A pronominalização ou nominalização são importantes recursos de coesão textual e estão diretamente relacionados ao encadeamento das ideias do texto e às referências que fazemos. Por 
isso, é ideal que se siga um fluxo, facilitando a leitura, pois quando há a sensação de fluidez, o texto não fica cansativo; assim, afirmamos que ele é coeso.

\section{MONOGRAFIA 04 \\ $\checkmark \quad$ Introdução}

Entre Gregos e Romanos, o ato de

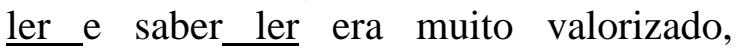
indicando base para uma educação adequada para a vida. Hoje não é diferente; a prática da leitura tornou-se objeto de muitos pesquisadores da área, como também a busca de estratégias para desenvolvê-la. Nesse sentido, procuram-se os meios para auxiliar os professores a promover, no ambiente escolar, a leitura mais criativa e revigorada.

A leitura é sem dúvida o caminho para uma formação completa do aluno, entretanto, como auxiliá-los a atingirem esta formação, diante de inúmeros fatores que dificultam esta aprendizagem como falta de investimentos no aprimoramento dos professores. Estes professores chegam a afirmar que há uma "crise da leitura" que seria o distanciamento do indivíduo do livro.

\section{$\checkmark \quad$ Considerações Finais}

Como vemos, a leitura é uma prática que foi se escolarizando, fato este que agregou mais responsabilidade ainda à escola, que algum tempo sente a necessidade de renovar-se para atender sua clientela em condições de constituir neles a rotina da leitura. Para tanto, faz-se necessário encontrar mecanismos que realizem a aproximação do aluno com a leitura nos seus mais variados suportes.

Análise:

Na monografia 04 , a repetição mais uma vez revela o desconhecimento de estratégias de referenciação que possam retomar o objeto-do-discurso sem necessariamente lançar mão de uma reprodução repetitiva. Percebe-se que na introdução e consideração final não se leva em conta esse princípio e, ao fazê-lo, contraria alguns princípios de textualidade que garantem o fluxo de informação nos textos. Em outras palavras, a repetição exaustiva e desnecessária de termos pode interromper e/ou afastar o próprio contato do leitor com o texto, rompendo assim sua maior finalidade. Para evitar isso, valemonos do recurso da referenciação ou retomada, ou seja, em vez de simplesmente repetir uma palavra já utilizada, fazemos referências que remetam a ela, no curso do texto.

\section{CONCLUSÕES}

O objetivo central neste artigo foi demonstrar que as estratégias de referenciação, utilizadas em textos escritos, facilitam entendimento e a compreensão das diferentes escolhas linguísticas utilizadas na construção de um enunciado ou texto. Esse processo argumentativo é a melhor maneira de conhecer as diferentes formas de organização dos aspectos linguístico-textuais de um gênero.

Os processos de retomada ou progressão referencial são muito importantes na construção, na argumentação e na finalização de um texto. Os primeiros levantamentos realizados, durante a fase de pesquisa e leitura acerca de algumas monografias e TCCs apresentados no curso de Letras da Universidade Estadual do Maranhão, mostrou-nos que alguns alunos apresentam dificuldades na retomada de uma temática proposta ou de um objeto do discurso.

Percebe-se, dessa maneira, que a grande dificuldade dos alunos está atrelada à falta de um repertório vocabular ou até mesmo de conhecimentos linguísticotextuais acerca do uso de estratégias que garantam uma progressão referencial adequada. Verifica-se uma pobreza vocabular, fruto, quem sabe, de um histórico de falta de leitura que possam ampliar esse repertório.

Esta pesquisa identificou as dificuldades encontradas pelos alunos na construção de suas introduções e conclusões de suas monografias, 
mostrando, principalmente, o desconhecimento de estratégias de retomadas nesses subgêneros textuais, tanto a temática ou problemática levantada na introdução que deveria ser explorada na conclusão quanto ao uso de termos que poderiam evitar a repetição do termo utilizado para o objeto do discurso. Com este estudo, será possível compreender e conhecer as diferentes estratégias de referenciação adotadas nas monografias selecionadas.

\section{REFERÊNCIAS}

ANTUNES, Irandé. Questões envolvidas na análise de textos. In: Análise de textos: Fundamentos e Práticas. São Paulo: Parábola Editorial, 2010.

BAZERMAN, Charles. Gêneros textuais, tipificação e interação. In: DIONISIO, Ângela Paiva e HOFFNAGEL, Judith Chambliss (Org.). São Paulo: Cortez, 2005.

MILLER, Carolyn R. Gênero Textual: Agência e Tecnologia. In: DIONISIO, Ângela Paiva e HOFFNAGEL, Judith (Org.). São Paulo: Parábola, 2012.

$\mathrm{KOCH}$, Ingedore Villaça. Escrita e progressão referencial. In: ELIAS, Vanda Maria (org.). Ler e Escrever: Estratégias de produção textual. São Paulo: Contexto, 2009.

KOCH, Ingedore Villaça. Gêneros Textuais. In: ELIAS, Vanda Maria (org.). Ler e Compreender: os sentidos do texto. São Paulo: Contexto, 2006. 